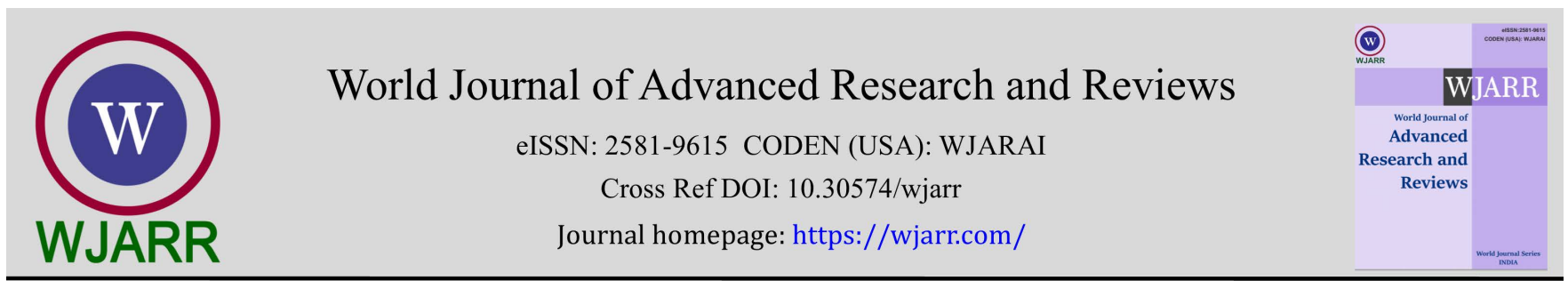

(RESEARCH ARTiClE)

Check for updates

\title{
A study of the utilization of community meeting as an interactive strategy in substance abuse management
}

\author{
Haa Nevin Terry 1, *, Makput Duwap ${ }^{2}$, Nantok Dami ${ }^{3}$, Caroline Maton 1, Panmun Dadem 1, Hanna Emmanuel 1 , \\ Victor Hosea Fwang'ar ${ }^{4}$, Sunday Dakama ${ }^{4}$ and Sarki Pandang ${ }^{5}$ \\ ${ }^{1}$ Centre for Addiction Treatment and Research Vom Christian Hospital, Jos, Nigeria. \\ 2 Department of Psychiatry, Jos University Teaching Hospital (JUTH), Jos, Nigeria. \\ ${ }^{3}$ Department of Community Medicine, Jos University Teaching Hospital (JUTH), Jos, Nigeria. \\ ${ }^{4}$ Department of General and Applied Psychology, Faculty of Social Sciences, University of Jos, Jos, Nigeria. \\ 5 Department of Psychology, Faculty of Social Sciences, Plateau State University, Bokkos, Nigeria.
}

World Journal of Advanced Research and Reviews, 2021, 11(01), 157-168

Publication history: Received on 20 May 2021; revised on 17 July 2021; accepted on 20 July 2021

Article DOI: https://doi.org/10.30574/wjarr.2021.11.1.0290

\begin{abstract}
In a treatment facility in Nigeria community meeting has been an effective strategy in substance abuse management for identifying and addressing motivation in the treatment, insight and judgment, self-esteem, psychotic symptoms, readiness for treatment etc. The components of community meeting significantly facilitate effective transition in stages of change. This research utilised information from various meetings, individual interviews and Focus Group Discussion. The study also obtained information about substance use from files of 211 participants previously admitted from 2014 - 2020, descriptive statistics using SPSS version 20 was utilized in the analysis. The analysis show that male were predominant at $91.9 \%$ with a mean of $1.08,24.6 \%$ primary substance of abuse is alcohol and the most common substance abused at $29 \%$. Clients admitted with psychotic symptoms were $47.9 \%$ and $29 \%$ common problematic substance is cannabis and $65 \%$ of them are within the ages of $21-30$ years, while $45 \%$ of them have used other psychoactive substances like opioids and cocaine. The qualitative study reveals that all the components of community meeting significantly contributed positively in the management of clients. Consequently, community meeting gives people experiencing addiction the opportunity to self-examine, express, and adapt to techniques of living a substance free life effectively. This gathering allows all categories of clients interact freely and respectfully given way to teaching, learning and mentoring. The researchers therefore, suggest that though substance abuse problems may not vary, however, the approach to addressing this problem should be tailored in a ways that reflects the people and their culture.
\end{abstract}

Keywords: Community Meeting, Substance, Management; Interactive strategy

\section{Introduction}

The social interaction of human beings is part of what makes them special, but communal life is a distinct quality common in African culture were members of a family or community lookout for each other. In Africa and Nigeria, Community parenting is key in addressing misconducts among young people by older adults. A community is formed when different family members come together to occupy a particular geographical area sharing common belief, identity, norms, values and resources. This therefore, suggest that when people from different families stay together with the aim of addressing a common challenge of collective interest then a community is born. These individuals may decide days, time and venue for meeting to discuss issues affecting them. This method of problem solving is similar with the concept of community meeting in some substance abuse facilities (rehabs) in Nigeria. The approach in community meeting is borrowed from the larger community setting of Nigeria but doctored to address substance abuse related

\footnotetext{
* Corresponding author: Nevin Terry Haa

Centre for Addiction Treatment and Research Vom Christian Hospital, Jos Nigeria.
} 
problems and psychological challenges. Operationally therefore, community meeting is the coming together of clients and staff within an inpatient residential treatment facility with the intention of addressing client's addiction, psychological and welfare related problems through sharing in talking.

Historically, community meeting as an intervention was the brain child of three individuals, [1, 2, 3] these people conceived the idea in England within the period of the Second World War because of the population that needed help for psychological problems as an aftermath of the war. In most residential treatment facilities in Nigeria community meeting is introduced to clients on admission as part of the programs of the facility for both staff and clients. The meeting last between 45 to 60 minutes on stipulated days [4, 5, 6]. According to Lipgar it is a "milieu therapy" [7]; psychoanalytic theory is the fulcrum upon which the "treatment" revolves this contributes to compliance in treatment and better psychological wellbeing [8].

Culture has however, shaped this pattern of treatment in Nigeria. According to Anita "what a people hold to be true, right or proper with regards to those things explains much of the cultural traits (values) by which they become identified" [9]. These "values" in Nigeria is the fulcrum around which every activity revolves. Because of previous beliefs in deities African religious values seems to permeate the very fabric of the African belief system which hold onto superstition. The believes in superstition for "unexplainable health" related problems like substance abuse comorbid mental illness and approval of licit substances for initiation and other cultural activities still lingers, therefore, to address these, a cultural approach is required to identify and solve these problems hence, community meeting.

Community meeting in some treatment facilities in Nigeria is structured into six major segments they are; Assessment/evaluation, concept (i.e. presentation), community Business, News and facts, questions, comments, affirmation and Pull-ups. The facilitator is nominated prior to every meeting to coordinate the smooth running of subsequent meeting. Figure 1 shows the structure of the community meeting.

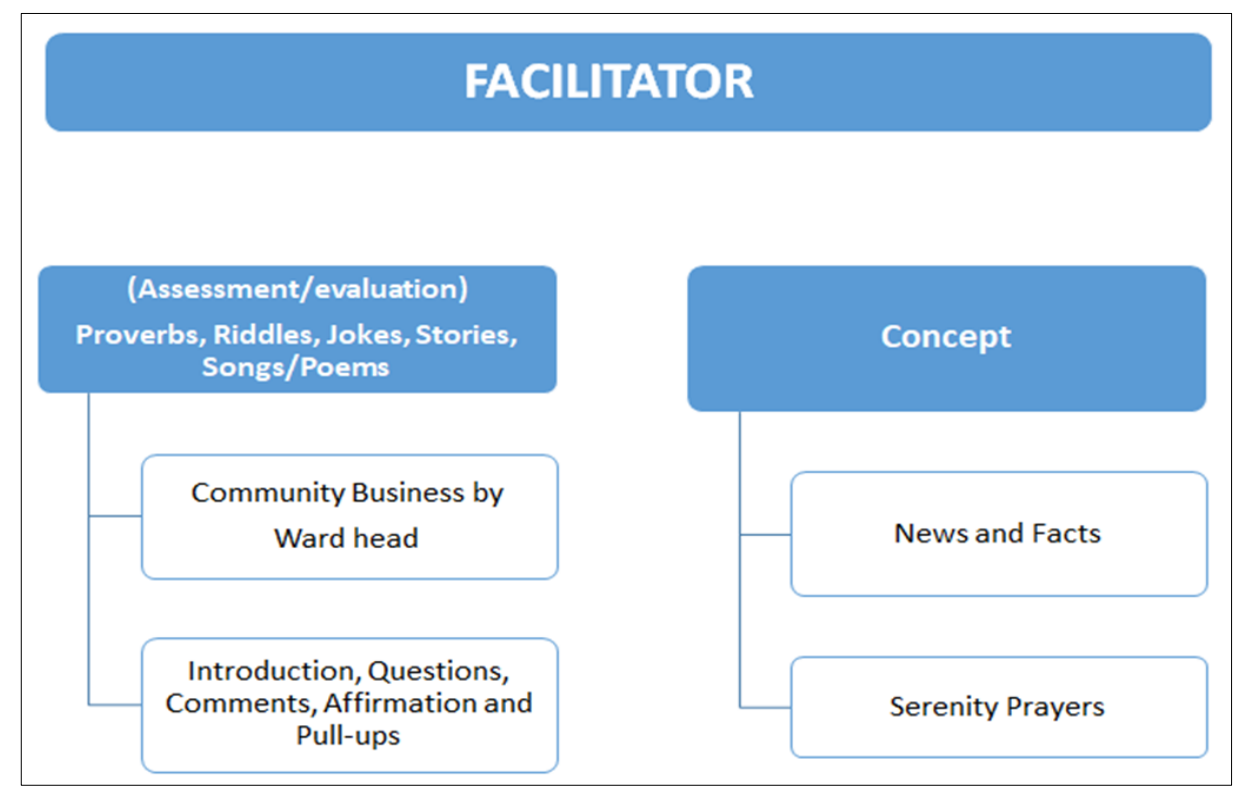

Figure 1 Structure of community meeting

The reason behind this structure is to evoke change, stimulate motivation, build self-esteem, develop insight and judgment, address psychotic symptoms, improve readiness for treatment and appreciate the power of prayers. In all of these the staff benefit understanding the client stages of change and extent of self-examination.

\section{How the structure of community meeting works?}

\subsection{Assessment/evaluation}

This is the first aspect of the community meeting, it is designed to examine the mental status of each client using the instrument of proverbs, riddle, songs, and poem. Each of these is key to African culture and tradition, proverbs are "a major source of African wisdom and a valuable part of African heritage" this is why this strategy was adopted [10]. 
During community meeting every client choose from one of these activities (either proverbs, songs etc.), thereafter the client explain the meaning of the proverb, reason behind the song sang, simplify the puzzle in a riddle or meaning of a poem depending on the activity of his/her choice. The explanation therein tells more about the mood of the client, decision about change and the stage of recovery owing to the meaning and explanation given. The meaning of the proverb, the lyrics in the song, the intrigue of a puzzle and stanzas in a poem reveals the conflict in the unconscious mind, the depth of self-examination and stage of change. Basically, the explanation by clients may suggest; i. compliance to treatment (optimism), ii. Resistance to treatment or iii. Superstitious belief. The cultural dimension is that; proverbs, songs, riddles, jokes etc. are for the wise and knowledgeable and forbids doing harm.

\subsection{Concept}

Concept is a short presentation by the client on topic of his/ her choice, it is the second aspect in the community meeting. The strategy supporting the inclusion of concept is to enable clients who took into substance abuse as a result of low self-esteem develop confidence and build assertiveness skills. Note that, self-esteem is the feeling of value or level of acceptance accorded to oneself [11].

\subsection{Community business}

The third part in community meeting is the interface between the staff and clients concerning welfare. The elected ward head spear heads this aspect. During community business the decisions regarding the limits and rights, betterment of working relationship between staff and clients and among clients can be sought out were differences occurs [7].

\subsection{News and Facts}

News has been another form of enlightenment for many decades by delivering information through the print, electronic and in recent times online as a way of keeping the public abreast with happening around the globe and immediate environment [12]. This aspect in community meeting is aimed at teaching, encouraging and involving clients in meaningful activities like listening to news, writing, reporting and discussing same during the gathering (of community meeting). The aim of including news and facts is to help client build the desire for responsible activities, also, restructuring client daily hourly schedule during treatment to reflect after discharge. This responsibility is also believed to help in addressing attention and concentration of client. "Facts" as it is called test intellectual ability of the client, common questions relating to current affaires are asked in order to examine client responses/intelligence [13].

\subsection{Introduction, comments, questions, affirmation and pull-ups}

This part of the community meeting gives newly admitted client the opportunity to be welcomed into the fold, to build a sense of belonging and feel at home while receiving treatment. Culturally speaking, introduction into a new group is referred to as initiation, it is done as cultural rites during traditional rituals to connect the new with the old. Furthermore, it exposes a new member to the rules and norms of the group [14]. This part of the community meeting also gives other clients the opportunity to make contributions or lay complains that where missed out by the ward head during community business. Again the client use this time to ask questions directly to staff or raise personal concern.

During affirmation, clients appreciate each other previous good behaviours towards one another, it serves as a period for reinforcing positive behaviours. However, any negative behaviour is frowned at and is punished during this time using pull-ups.

\subsection{Statement of problem}

In Nigeria research on community meeting has not been given much attention, the paucity of scientific evidence to prove its effectiveness to substance abuse management has not been properly utilized. Furthermore, poor understanding by many mental health professionals of the psychological component of community meeting, its significance to clients and staff has resulted to the undermining of the essence of this all important 'milieu therapy'. Research has shown that in Nigeria about 14.3 million of the population that is $14.4 \%$ use substance and are mostly youth between the ages of 16 years and above, however, only $40 \%$ nationally were interested in seeking treatment [15]. This implies that less than $40 \%$ are likely to benefit from facilities that effectively apply community meeting as a "milieu therapy" for substance abuse management. The use of culture in this study will cover the gap that other previous research never viewed.

\subsection{Conceptual framework}

This study adopts the psychodynamic paradigm which is an upshot of the Sigmund Freud psychoanalytic theory. The psychodynamic paradigm posits that, the manifestation of human behaviour has a root from the unconscious mind, implying that the outward person is the reflection of the inner person and vice versa. Generally speaking, overt 
behaviour is the product of the unconscious mind [16]. By and large, every human behaviour has a motive and when there is a reoccurrence of a specific behaviour then there is a specific drive controlling it.

Psychodynamics is a useful paradigm in explaining community meeting because the elements that make up the meeting elicit trajectory of; compliance or optimism, resistance and superstition. This is influential to understanding so much about each client's unconscious mind which cannot be overemphasised [17]. The application of the psychodynamic is necessitated by the value attributed to the meeting by clients and the importance of communal life in Nigeria.

\section{Aim of the study}

The study is aimed at examining the usefulness of community meeting in alcohol and substance addiction management and improve the understanding of mental health professionals of this all-important activity. In order to improve how mental health professionals, manage clients experiencing addiction, the study explains the effectiveness of community meeting and how it can serve as a means of understanding and facilitating client's recovery. This study hopes to bring a clearer view of the vitality of community meeting in addiction management.

\subsection{Research questions}

- How will participation in community meeting improve self-esteem in client in the course of substance abuse management?

- How will participation in community meeting result in self-examination?

- How will participation in community meeting help client develop insight and judgement during substance abuse use management?

- Will community meeting be necessary for understanding clients' compliance during substance abuse management?

- Will Community meeting give mental health professional an understanding of clients that are unwilling to comply with substance abuse management?

- Will community meeting be an avenue for understanding clients with superstitious beliefs toward substance abuse comorbid mental illness?

- How will assessment and evaluation of clients during community meeting be determine by their interpretation of proverbs and wise sayings?

- Will the nature of community meeting align with some of the cultural practices of the clients?

\subsection{Hypotheses}

- There is the likelihood that participation in community meeting will improve self-esteem in client in the course of substance abuse management.

- There is the possibility that participation in community meeting will result in self-examination.

- There is the possibility that participation in community meeting will help client develop insight and judgement during substance abuse management.

- There is the likelihood that community meeting may be necessary for understanding clients' compliance during substance abuse management.

- Community meeting will give mental health professionals an understanding of clients that are unwilling to comply with substance abuse management.

- Community meeting will be an avenue for understanding clients with superstitious beliefs toward substance abuse comorbid mental illness.

- The assessment and evaluation of clients during community meeting may be determine by their interpretation of proverbs and wise sayings.

- There is the likelihood that the nature of community meeting will align with some of the cultural practices of the clients.

\subsection{Research design}

This study is a mixed design, the observational method and descriptive statistics of clients admitted within the period under review was utilized. The reason for using the observational method is to record ongoing behaviour during 
community meeting with the aim of understanding clients' behaviour without controlling or intruding in any way. The researchers observe naturally how the behaviour of each client occurred within 60 minutes of community meeting for a minimum period of 90 days in an inpatient alcohol and substance abuse facility in North-Central Nigeria.

The observational approach gave the researchers the opportunity for a better understanding of the experience of participants. This approach gives enough room for acceptance because both the researchers and the clients are members of the therapeutic community and actively participated in the community meeting in its entirety. Within the period under investigation the researchers studied the behaviours and treatment progression of every participant from the first day on admission to the last day to discharge. Treatment last between a minimum period of three months to a maximum period of 12 months especially in severe cases of dual diagnoses. Within these periods the clients are expected to actively participate in community meeting.

\subsection{Sampling technique}

The research used a purposive sampling technique, a non- probability method in selecting participants of interest for the interview. A total of 14 clients were interviewed, 6 participated in the one-on-one interview and 8 participants were selected for the focus group discussion. Meanwhile, demographic information was obtained from medical files. The demographic information was obtained from 211 files. The use of purposive sampling is to enable the researchers get an in-depth insight into the phenomenon under study. The researchers stroked a balance between the gender of participants for the one on one interview ( 3 males and 3 females).

\subsection{Participants}

The Participants of this study are drawn from Centre for Addiction Treatment and Research (CATR) Vom Plateau State, North Central, Nigeria, with interest in people who are admitted for alcohol and substance abuse. 194 of the admitted clients are males and 17 females, they are within the ages of 16 to 65 years. These participants are observed during their weekly participation in community meeting regardless of their state of stability.

\subsection{Data collection}

The researchers got a verbal permission from the 14 participants; 6 for the one on one interview and 8 for the focus group discussion who volunteered information. After the one on one interview the response was replayed to each participant separately to ensure that the responses were correct and approved for the study, this was aimed at avoiding misrepresentation of information. The responses of participants were transcribed and quoted verbatim in the result section in line with the experience of the clients and purpose of the study. The one on one interview was carried out simultaneously by co-researchers to avoid response bias and lasted for a period of 5 to 10 minutes. Participants answered open-ended question that aimed to meet the purpose of the research, and the response were recorded in a recording device and later analysed using Interpretative Phenomenological Analysis (IPA).

The focus group discussion consists of participants from different ethnic background within Nigeria. One of the researchers moderated during the exercise while other co-researchers assisted with taking notes and controlling recording equipment. All reactions both verbal and non-verbal responses relevant to the study were recorded, thereafter the discussion was summarised, reviewed to double check unaddressed issues and finally all participants were appreciated verbally. Other relevant information's were obtained from the researchers' participation in community meetings. In order to bring a level of objectivity into the study; diary was used to record client individual proverbs, concepts and other contributions during the meeting. Demographic information; sex, substance abuse of dependence, substance abuse comorbid psychotic symptoms and age were obtained from the medical files of client admitted from 2015 to 2020 .

\section{Method of data analysis}

The research utilized the Interpretative Phenomenological Analysis (IPA) in interpreting the information obtained from the interviews and focus group discussion. First and foremost, the study listened to the audio recording repeatedly in order to get the information properly and transcribed them appropriately. Thereafter, the audio massage and the paper transcription were compared in order to be certain of the information received and transcribed. Then the study took notes at first so as to stay within the experience of the participants. During this exercise some of the phrases and sentences considered relevant were highlighted before adding the comment by the research. Furthermore, the description of the interview from participants resulted to themes from the transcript. Lastly, the study classified the themes across the transcripts by way of comparing and identifying places were similarities and differences occurred, these were grouped according to their relevance and thereafter quoted word to word in places necessary. Discuss 
Analysis (DA) was used to articulate the information from FGD, the two information from face to face interview and FGD were harmonise in the result section.

\section{Results/Findings}

The first set of result represents a descriptive statistics and frequencies of clients experiencing substance addiction that were admitted into the facility. Statistical result from this study revealed that, of the 211 files, $91.9 \%$ are males and $8.1 \%$ are females, the mean score for sex is 1.08 and standard deviation .273. From this population client admitted for substance dependence are 110 that is $52.1 \%$ while those with substance abuse comorbid psychotic symptoms make up $47.9 \%$ that is $101.7 .1 \%$ are within the ages of 10 to $20,45.0 \%$ are within the ages of 21 to $30,36.5 \%$ are between the age of 31 to $40,8.1 \%$ are between 41 to 50 years of age, then .5\% are within the age of 51 to 60 and $1.4 \%$ are between 61 to 70 years of age. The mean score for age was calculated at 2.53 and a standard deviation of .873. Below is the representation of themes in table 1.

Table 1 Presentation of Themes

\begin{tabular}{|l|l|l|}
\hline \multicolumn{1}{|c|}{ Super-ordinate themes } & \multicolumn{1}{|c|}{ Emergent themes } & \multicolumn{1}{|c|}{ Sub-themes } \\
\hline $\begin{array}{l}\text { Clients and Community } \\
\text { meeting }\end{array}$ & $\begin{array}{l}\text { Community meeting a platform for } \\
\text { self-esteem }\end{array}$ & Concept as an aspect \\
\hline & $\begin{array}{l}\text { Self-examination as impact of the } \\
\text { meeting }\end{array}$ & Proverbs and wise sayings help \\
\hline $\begin{array}{l}\text { Making meaning of client's } \\
\text { participation in community } \\
\text { meeting }\end{array}$ & $\begin{array}{l}\text { Compliance and readiness for } \\
\text { treatment }\end{array}$ & \\
\hline & comments made from resistance & \\
\hline & Superstition, not been normal & Interpretation matters \\
\hline $\begin{array}{l}\text { The culture in community } \\
\text { meeting }\end{array}$ & How it applies & $\begin{array}{l}\text { Pull-ups, songs, proverbs/wise } \\
\text { saying and jokes }\end{array}$ \\
\hline
\end{tabular}

The following results were obtained from keen participation of the researchers during community meetings, one on one interviews and focus group discussion. The participants in this research shared their experiences on community meeting. This research view community meeting as an integral part of a client's 'substance abuse use management' modalities that shapes decision about staying abstinent and enable them have a positive view of a future without substance abuse. The researchers seek to understand the meaning behind every covert and overt behaviour during community meeting.

\subsection{Clients and Community meeting}

Question: Kindly describe how community meetings is impacting you?

P2: "It gives me an idea on how other clients think through their opinion from proverbs riddles and songs."

P5: "We share ideas that I haven't heard of and we get advice from the workers that we never knew about...."

P6: "Community Meeting helps me to understand things... the more regularly you attend community meeting the more develop your level of understanding will be."

\subsection{Community meeting a platform for self-esteem}

Question: "kindly describe how community meetings contributed towards building your self-esteem"

P6: “...it gives a sense of self-confidence, you understand? Community meeting help you to build self-confidence... when you stand to share your opinion" 
P3: "Community meeting is the very best channel to boost self-esteem why I say so, addiction in general comes with low self-esteem... community meeting, gives me the opportunity to show case myself in front of the crowd...... I never thought I could stand it before time. There was this low esteem in me..... after presenting my "concept" about humility I felt this sigh of relief, I felt bold deep down inside."

\subsection{Concept as an aspect}

Question: please can you tell me the aspect of community meeting that appeal to you?

P1: "Yes like the part of "concept" I use to be scared but now I can stand and talk without been scared."

P4: "Some of the "concepts" are highly respected if you work through them you will understand what life is"

\subsection{Self-examination as impact of the meeting}

Question: Please can you describe how community meeting helped you in self-evaluation?

P1: "Yes when someone say something you actually relate it to yourself, am I really doing the right thing or not...I learn how to correct myself and move on with life."

P2: "I get to hear one or two things that makes me go back and think; from wise saying affirmation etc. that gives me a reason to cross examine once a while."

\subsection{Proverbs and wise sayings help}

Question: "what is the role of proverbs to you in community meeting?"

P5: "Most of the proverbs and wise saying that we do share with each other... I do evaluate what they have said that will help me in life and in my recovery."

P6: "...the one that I will referred to that has help me most is the time of proverbs and wise saying... because all these proverbs or wise saying are nugget of truth they are basic tools that one needs to cope with life, they are truths about life..."

\subsection{Benefits to insight and judgment}

Question: “Can you share with me how community meeting built your insight and judgment?"

P1: "I have learnt how substance abuse affects health especially for us females and how the family suffers from our substance use."

P2: "In a way when I see how others react during community meeting it tells me how substance abuse can damage a person."

\section{Making meaning of client's participation in community meeting}

\subsection{Compliance and readiness for treatment}

The researchers observed during the meeting that client who are optimistic and ready for life style change give proverbs that will motivate and encourage adherence in their management, example are the following:

P1: Proverb: "the patient dog eat the fattest bone"

Interpretation: "if I remain patient while on treatment, I believe I can be patient not taking substances"

P3: Proverb: "never get tied down by what you have done, always keep looking up"

Interpretation: "be hopeful that things will turn out better after substance abuse management" 
P2: Proverb: "Fool me once shame on you, fool me twice shame on me"

Interpretation: "I should learn a lesson from my first mistake that led to relapse and learn not to allow it repeat again"

Proverb: "a patient man can cook a stone and drink from it source"

Interpretation:" patient is a virtue any man or woman with patience is likely to succeed in every situation and also get things accomplished not minding how long it will take to be accomplished."

\subsection{Comments made out of resistance mind}

When clients are tricked by family members into treatment they turn out to avoid every treatment programs of the facility however, if they attend their proverbs reveals their state of resistance as presented below.

P: Proverb: “you can force a horse to the stream but you can't force it to drink"

Interpretation: "my parents can bring me here but if I will change I will change nobody can force me to change."

P: Proverb: "every garden egg will turn red except it is not expose to sun light"

Interpretation: "we all have the potential of doing wrong except the situation does not present itself."

\subsection{Superstition, not been normal}

Most clients in the treatment that attribute their health challenge to the supernatural are tilted to give wise sayings, proverbs or "concept" in a manner that suggest a belief in the superstition, like in the observation below which was from researchers participation in community meeting:

P9: Proverb: "the one whom the gods hate, they first make him mad"

Interpretation: "most people that have mental illness- it is my kens men, they brought this upon me"

From the proverbs and interpretations above it is easy to determine client stage of recovery and mental stability.

Concept: Topic-“Witches and wizards”, “Discipline”, “Delay”, "Humility”

\subsection{Focus group discussion}

The researcher seek to understand how community meeting as strategy applied to the culture of the clients. Participants for this discussion share cultural experiences that align with this important activity. The following are their responses:

\subsection{The culture in community meeting}

\subsubsection{How it applies}

P4 “...Almost all the agenda or programme that we have here from facilitator down to prayers they are programme or activities that are been done even in our culture but with different dimension not as it is written"

P6 "....we have the facilitator who is normally like the MC (master of the ceremony)...he is the one that will come and start the event and welcome everybody and then the event will start."

\subsection{Songs, proverbs/wise saying and jokes:}

P6..."in my culture too during our meetings the various traditional groups comes to sing songs and dance round-round before the whole program is started."

P4 "...and as of that of the wise saying and proverbs ...there are songs that during the dance are been spoken of like proverbs or some kind of wise saying but in song pattern...in that everybody understands..." 


\subsection{Pull-ups}

P1: Pull-ups: "like the pull-ups, when we were small they use to do it...If you are disobeying your parent, your parents will include your name there... if you do anything bad they will pull you...so that you correct that thing, so that somebody will not repeat that same thing. If you steal your father can take it there, if your father is a drunkard and family doesn't like it or you do something bad they will go and punish you there."

\section{Discussion}

\subsection{Community meeting a platform for Self-esteem}

The first hypothesis raised stated that "There is the likelihood that participation in community meeting will improve selfesteem in substance abuse management" this hypothesis is significant. Respondents expressed their interest in community meeting because of the immense benefit associated with building self-worth, thereby, overcoming the problem associated to low self-esteem that led them into substances e.g. "Community meeting is the very best channel to boost self-esteem why I say so, addiction in general comes with low self-esteem... community meeting, gives me the opportunity to show case myself in front of the crowd..... I never thought I could stand it before time. There was this low esteem in me.... after presenting my "concept" about humility I felt this sigh of relief, I felt bold deep down inside." This is in line with previous studies which posit that Self-esteem is a major component in treatment that determine how well a client transits from one stage of change to another [18]. This is because among other reasons low self-esteem is a significant associate of substance abuse therefore, self-esteem contributes to self-evaluation emotionally and psychologically.

\subsection{Self-examination; the impact from community meeting}

The second hypothesis which says "There is the possibility that participation in community meeting will result in selfexamination" is significant. Taking inventory of personal life and re-examining one-self, help in changing a negative mind to a positive one. This ability to self-examine is uncommon because of the negative effects of substance abuse on cognition, although community meeting play a good role in reversing this e.g. "I get to hear one or two things that makes me go back and think; from wise saying affirmation etc. that gives me a reason to cross examine once a while." Other studies support this view, according to them human by nature often subject their emotion and thoughts to subjective evaluation known as self-examination [19]. Self-examination, which project critical mental process enables individuals and clients learn and understand more about self either in the moment or past [20], this opportunity for self-recognition emotionally, cognitively etc. is vitally critical for client experiencing substance addiction and beneficial for substance addiction management [21] and community meeting provide this avenue using proverbs, wise sayings, riddles etc.

\subsection{Gaining insight and judgment}

The third hypothesis which says "There is the possibility that participation in community meeting will help client develop insight and judgement during substance abuse management" is significant. Insight for a client is said to develop when he or she is able to come to terms with the reason that led to the treatment and indicate interest in making positive changes, however, as for judgement the client is able to decipher making good decision in critical situations. This may include but not limited to answering of questions from riddles and jokes during community meeting e.g. "I have learnt how substance abuse affects health especially for us females and how the family suffers from our substance use." Insight is the awareness that comes with the nature of an illness, cause(s), functioning and willingness to accept and comply with treatment, meanwhile judgement is measured when client can answer puzzles in a scenario [22], in community meeting, riddles surface for these.

\subsection{Compliance, the context of researchers}

The forth hypothesis stated that "There is the likelihood that community meeting may be necessary for understanding clients' compliance during substance abuse management" this hypothesis is significant as quoted from a participant "I should learn a lesson from my first mistake that led to relapse and learn not to allow it repeat again". During community meetings it is not difficult to identify clients who are determine to change, their commitment during the meeting and contributions clearly reveal where the interest in them lies. This vital information is obtained through proverbs/wise sayings, songs or concepts etc. these activities enable client's pour out their inner feelings harmlessly and positively. Participants in this study were observed and their contributions over a period of 3 months suggest willingness for a positive change. Researchers in this study observed that client's contribution should be considered as a good measure for determining their recovery stage. Although compliance and optimism has received many definitions from different quarters the meaning has remain the same. For most clients in this category their proverbs, songs etc. gives hope and 
anticipation of a better future. Compliance to treatment includes but not limited to keeping to appointment for community meeting, adhering to medication and other treatment regimens [23].

\subsection{Resistance comments}

The fifth hypothesis that says "Community meeting will give mental health professionals an understanding of clients that are unwilling to comply with substance abuse management" this hypothesis is significant. Community meeting is actually a mix grill, a place where both the motivated and unmotivated converge to interact respectfully. At the other side of the spectrum are clients who do not believe in the nature of the treatment either because they are experiencing psychotic or withdrawal symptoms. Using proverbs/wise sayings, songs, poem etc. researchers were able to draw finding that client not interested in the treatment not only avoid meetings but when they attend their contribution debase hope e.g. "you can force a horse to the stream but you can't force it to drink" "my parents can bring me here but if I will change I will change nobody can force me to change.". Research discovered that the reason with non-compliance is related to literacy level of the individual to the substance abused and formal education [24]. In a study on 283 participants on substance abuse treatment referral indicated that only about $20.5 \%$ consented to the treatment while over $80 \%$ gave varied excuses to decline or resist treatment [25].

\subsection{Superstition, not been normal}

The sixth hypothesis which says "community meeting will be an avenue for understanding clients with superstitious beliefs toward substance abuse comorbid mental illness" is significant. The inability to understand substance addiction as disease of the brain, the biological causes and nature of mental illness give way to the believe in spirits as the cause for addiction and mental illness since it is characterised by talking to self, social isolation and or an individual belief in been extraordinary as observed in this proverb and interpretation; "the one whom the gods hate, they first make him mad. "most people that have mental illness- it is my kens men, they brought this upon me". Superstition are connected to inexplicable natural phenomena's in life like mental illness, more so, lack of confidence, threats and fear results to superstition [26].

\subsection{Interpretation matters}

The seventh hypothesis which says, "The assessment and evaluation of clients during community meeting may be determine by their interpretation of proverbs and wise sayings" is significant. In all of the activities during the community meetings one important factor that is a determinant of were a client belongs or stage of recovery in the treatment is in the ability of the client to interpret appropriately from any of the proverbs, wise sayings, riddles, facts or answer questions after presentation (Concept) "It gives me an idea on how other clients think through their opinion from proverbs riddles and songs.". Even though interpretation may differ this may largely be due to perception toward treatment and mental stability. It is suggested that, the meaning of life can be obtained from the interpretation of what others say [27]. The depth of any truth can only be derived from the meaning given in a proverb [28].

\subsection{The culture in community meeting}

The eight hypothesis which says "There is the likelihood that the nature of community meeting will align with some of the cultural practices of the clients" is significant. Most of the cultural practices in Nigeria appear the same, the norms, values and taboos. Quote from participants support this hypothesis "...Almost all the agenda or programme that we have here from facilitator down to prayers they are programme or activities that are been done even in our culture but with different dimension not as it is written" also, "in my culture too during our meetings the various traditional groups comes to sing songs and dance round-round before the whole program is started." In recognition of this truth Anita added that "what a people hold to be true, right or proper with regards to those things explains much of the cultural traits (values) by which they become identified' [8].

\section{Conclusion}

Community meeting is a vital inpatient treatment modality in most facilities in Nigeria, this study therefore, has amplified the significance of this all important "therapeutic milieu". There is enough evidence suggesting that community meeting if well handled by staff can improve client's insight/judgement, motivation in the treatment, selfesteem, etc. especially when it is tailored according to the culture of the people. Over and above all, some of the existing gap and paucity of scientific evidence about community meeting is well covered here. The outcome identified through participants of all ages and tribe indicates that community meeting can be another way of intervention in mental health if adopted as a "communal therapy". 


\section{Compliance with ethical standards}

\section{Acknowledgments}

Our sincere appreciation goes to the management of the Centre for Addiction Treatment and Research, Vom Christian Hospital Jos-Nigeria and client who volunteered information that contributed to the success of this work, there is no limit to how grateful we are.

\section{Disclosure of conflict of interest}

There was no conflict of interest in the research, all authors came to a consensus before the content of the work was considered for publication.

\section{Statement of informed consent}

All the participant in the study gave their consent verbally.

\section{References}

[1] Jones M. A passing glance at the therapeutic community in 1964. International journal of group psychotherapy. 1 Jan 1965; 15(1): 5-10.

[2] Bion WR. Experiences in groups. London. Tavistock Publications. Journal of the American Psychoanalytic Association. 1961; 4: 887-909.

[3] Foulkes SH. My philosophy in psychotherapy. InFoundations of Group Analysis for the Twenty-First Century 15 May 2018; 43-51.

[4] Harms S, Benson A. The clients' experience of the community group: implications for nurse facilitators. Journal of Psychiatric and mental health Nursing. Feb 2003; 10(1): 49-56.

[5] Kisch J, Kroll J, Gross R, Carey K. In-patient community meetings: Problems and purposes. British Journal of Medical Psychology. Dec 1981; 54(4): 35-40.

[6] Novakovic A, Francis K, Clark J, Craig L. Community meetings on acute psychiatric wards: a therapeutic intervention or a meaningless exercise?. Mental Health Review Journal. 2010 Nov 17.

[7] Lipgar RM. Guide to patient-staff large group meetings: A sociotherapeutic approach. Group Dynamics: Theory, Research, and Practice. Mar 1999; 3(1): 51.

[8] Winer JA, Klamen DL. Interpretive psychotherapy in the inpatient community meeting on a short-term unit. Psychiatric services (Washington, DC). 1 Jan 1997; 48(1): 91-2.

[9] Antia OR. Akwa Ibom Cultural Heritage: Its Incursion by Western Culture and its Renaissance. Uyo: Abbny Publishers. 2005.

[10] Mbiti JS. African oral Literature. éditeur non identifié. 1977.

[11] Adler N, Stewart J. Self-esteem. Retrieved August. 2004 Mar; 27: 2009.

[12] Tanikawa M. What is news? What is the newspaper? The physical, functional, and stylistic transformation of print newspapers, 1988-2013. International Journal of Communication. 2017 Sep 14; 11: 22.

[13] LaBruzza AL. Using DSM-IV: A clinician's guide to psychiatric diagnosis. Jason Aronson. 1994.

[14] Ikwuagwu OA. Initiation in African traditional religion. Bamberg: Echter Verlag. 2007.

[15] Nigerian Bureau of Statistics Substance abuse in Nigeria Survey Report. 29 Jan 2019.

[16] Freud S. The interpretation of dreams, vol. 4. Standard edition. Strachery, James (trans.), (London: Hogarth. 1900; 254: 46.

[17] Erikson, E. H. Growth and crises of the "healthy personality." In M. J. E. Senn (Ed.), Symposium on the healthy personality 1950.

[18] Hewitt JP. The encyclopedia of Positive Psychology, volume II, LZ. United Kingdom: Willey-Blackwell. 2009.

[19] Schultz M. On studying organizational cultures: Diagnosis and understanding. Walter de Gruyter. 25 Oct 2012. 
[20] Zalta EN. The Stanford Encyclopedia of Philosophy. 2016. https://plato. stanford. edu. 2019.

[21] Banks WP, editor. Encyclopedia of consciousness. Academic Press. 2009 Mar 26.

[22] Finney GR, Minagar A, Heilman KM. Assessment of mental status. Neurologic clinics. 2016 Feb.

[23] Deci EL, Ryan RM. The" what" and" why" of goal pursuits: Human needs and the self-determination of behavior. Psychological inquiry. 2000 Oct 1; 11(4): 227-68.

[24] Leslie, Toby, Mohammad Abdur Rab, Hayat Ahmadzai, Naeem Durrani, Mohammad Fayaz, Jan Kolaczinski, and Mark Rowland. "Compliance with 14-day primaquine therapy for radical cure of vivax malaria-a randomized placebo-controlled trial comparing unsupervised with supervised treatment." Transactions of the Royal Society of Tropical Medicine and Hygiene. 2004; 98(3): 168-173.

[25] Boyle K, Polinsky ML, Hser YI. Resistance to drug abuse treatment: A comparison of drug users who accept or decline treatment referral assessment. Journal of Drug Issues. 2000 Jul; 30(3): 555-74.

[26] Newman T. Bubonic plague: third case reported in China. Medical News Today, Healthline Media UK, Brighton, United Kingdom.

[27] Strawson, P. F. Laws and Explanation in History 1959.

[28] Lugira AM. African Religion: A Prolegomental Essay on the Emergence and Meaning of African Autochthonous Religions. Omenana. 1981. 